\title{
Risk assessment of the cities of Estonia and the UK: comparative study
}

\author{
A. Tammepuu ${ }^{1}$, K. Sepp ${ }^{1}$, R. Paasoja ${ }^{2}$ \& V. Kuusemets ${ }^{1}$ \\ ${ }^{1}$ Estonian University of Life Sciences, Estonia \\ ${ }^{2}$ Tallinn University of Technology, Estonia
}

\begin{abstract}
This paper presents a comparative study of city risk assessment in Estonia, as a so-called 'new member' and in the UK as an 'old member' of the EU. The comparison of the outcomes was carried out on the basis of four strategically selected risk assessments of Estonian cities and the same number of British cities. The selected indicators of comparison were legislative requirements, provision and performance, methodologies, types of analysed risks, risk assessment outcomes on a wide scale, risk assessment results, usage of risk matrixes and also publication and availability.

The risk assessments in both countries were required not only on a local community level, but on regional and state levels as well. In the UK the legal requirements and anchors in methodology were in general more clearly defined, which guarantees the similarity and better compatibility of the risk assessments of different cities and parishes. For example the division of risk matrix between risk rankings is precisely determined in British methodology, however in the Estonian, different interpretations are currently allowable. British legislation also sets concrete requirements for the publication of the community risk register, but in Estonia the availability of similar material depends on the decision and good will of the local government.

The final conclusion is that the territorial risk assessment methodologies of different European countries cannot be overtaken one-for-one or converted. At the same time, British risk assessment methodology and organisation can undoubtedly serve as one of the examples in the process of the further development of territorial risk assessment methodology in Estonia and maybe also for other 'new members' of the European Union, as was previously expected.
\end{abstract}

Keywords: risk assessment, civil protection, public safety. 


\section{Introduction}

Sustainable development of cities and other urban units or urban settlements as complex systems depends on a large amount of characteristics and presumes relatively stabile conditions. Major accidents and hazards are samples of the destabilising factors, which can cause serious setbacks and breakdowns in the continuous development process. The risks, hazards and threats can be hidden and out of the eye of public attention until something serious happens. Therefore it is important for communities to be aware of these risks. For that purpose risk assessment is an essential part of civil protection [1]. In many European countries the usefulness of the further development of risk assessment in the field of civil protection and emergency preparedness is clearly recognized [2].

A lot of studies have been carried out concerning risk assessment in civil protection in the urban environment. Most of these concern concrete accident types, for example major chemical accidents, according to the "SEVESO II" Directive [3]. Fewer studies are available concerning the integrated approach of multi-hazard territorial risk assessment and management and also comparative studies. Lonka et al have conducted a comparative study of risk assessment in the field of civil protection of European countries [2]. The European research project QUARTER concentrated on the development of a territorial management system for territorial risk reduction and environmental quality improvement [4]. In the frames of the previously mentioned research project, a methodological framework for territorial vulnerability analysis and assessment was worked out [5]. In the context of territorial vulnerability analysis the Environmental Risk Management System procedure was proposed by the research group [6]. In Estonia Tint et al have discussed the problems of major accident hazards on the basis of Tallinn city risk assessments [7]. Tammepuu et al studied the aspects of risk assessment in land use planning, based on Tartu's city risk assessment and engaging different emergency risk types [1].

The authors of the current paper have been involved in the risk assessments of Estonian cities, communities and counties for several years. During our practical and research work we have noticed the remarkable differences between risk assessment outputs, based on the same methodology. Therefore we decided to study the problem more thoroughly, carrying out a comparative study of the largest cities of Estonia's four rescue regions: Tallinn (North -Estonia), Tartu (South-Estonia), Narva (together with Vaivara municipality, East- Estonia) and Pärnu (West-Estonia). After beginning the research we found it would be useful to compare the risk assessments in turn with the analogical work of another country, preferably 'an old' member of the EU.

After some casting about for a suitable country for comparison our eye stopped on the United Kingdom. Although the UK is very different from Estonia, being approximately 5.4 times larger by territory and 45 times by population, the countries still have enough similar features, favouring the comparison. Both countries are situated generically in the northern part of Europe, have a long coastal line, a low proportion of seismic and an absence of volcanic hazards, etc. In UK the performance of territorial risk assessment is 
shared between local resilience areas. Therefore, in the context of the study, we had to look for cases where the local resilience areas coincided with the territories of the cities or conurbations, including also surrounding urban areas. The selected areas were: (the boroughs of) London, Greater Manchester, West Midlands conurbation (Birmingham with surrounding urban areas), and Belfast. The last was chosen as differences exist in the requirements and methodologies for Scotland and Northern Ireland.

The essential goal of the study was finding out, analysing and discussing the parallels and dissimilarities between the different risk assessments and assessed risks of the cities of two European countries and to look for new ideas for proposals for the improvement and development of Estonian territorial risk assessment methodology.

The research materials were legislative acts and regulations, guides, risk assessment reports of Estonian cities and community risk registers with supplementary materials from British cities (incl. the boroughs in London) and conurbations.

\section{Legislative requirements for risk assessment}

The requirements for risk assessment in the field of emergency preparedness and crisis regulation in Estonia are enacted in the Emergency Preparedness Act. The Estonian Emergency Preparedness Act designates risk assessment as an important task of crisis management, on the basis of which all of the following measures should be planned and implemented [8]. The act places the duty to conduct risk assessments of cities and rural municipalities on local governments. The rural municipality or city government has to perform risk assessments in order to identify the dangers, which may exist in the rural municipality or city, respectively. The outcomes of territorial risk assessment will serve as the basis for composing crisis management plans and spatial (land use) planning, concerning county plans, comprehensive plans, detailed plans, and also specific building projects. The act does not enact duties concerning the public availability of risk assessment issues in any form nor sets any restrictions.

The British Civil Contingencies Act 2004 [9] places a risk assessment duty on all Category 1 responders. The Category 1 responders are generically the following institutions: emergency services, local authorities, health bodies and environment agencies [10]. These Category 1 responders are obliged to assess risk from time to time, but as often as is necessary to ensure that they are in a reasonable position to maintain and update their emergency plans and to perform the civil protection duties under the Act, including the duty to maintain business continuity plans. The Category 1 responders also have an obligation to arrange for the publication of all or part of (risk) assessments made, simultaneously considering the security classification of the information and the restrictions on the disclosure of sensitive information. The requirements are detailed in The Civil Contingencies Act 2004 (Contingency Planning) Regulations 2005 [11]. 


\section{Risk assessment methodologies}

\subsection{General overview}

The methodological basis of territorial risk assessment in Estonia is established by a regulation of the Minister of the Interior. In the methodology legislation, risk assessment is defined as the systematic determination and evaluation of possible accidents and risk sources and the planning of measures for their prevention [12]. The methodology is largely based on the UNEP/APELL guidebook: Hazard Identification and Evaluation in a Local Community [13], of which the Estonian translation was organized in cooperation with the Estonian Rescue Board and Swedish Rescue Board.

The methodologies in the UK are presented in different issues. The methodologies for England and Wales can be found from the emergency preparedness guidance as a corresponding chapter [14] and the same for Scotland [16]. Northern Ireland has its own special (draft) guidance for risk assessment [15]. The methodologies have different elements, but in general the main principles are the same, partially adopted from the standard used in Australia and New Zealand. To facilitate our approach we dwell primarily on the English (and Welsh) version.

Our preliminary comparison demonstrated the existence of abundant similarities between the methodologies of the observed countries. Parallels can be drawn between the steps of assessment and the elements of risk evaluation. Both countries use five-point scales for likelihood and consequences assessment, which are combined into the five-times-five risk matrix. The following comparison is based on succeeding characteristics: steps, assessed risk types and categories, likelihood assessment, consequence assessment, the outcomes, output documents.

\subsection{Steps of risk assessment}

Estonian methodology requires the risk assessment as a 7-step process. British methodology consists of 6 defined steps. The first steps in the methodologies are expressed differently, but there is much in common between them as the Estonian information collecting (and exploitation) function is partially similar to British contextualisation - "describing the characteristics of the local area that will influence the likelihood and impact of an emergency in the community" [14]. The British 3rd step - risk analysis, covers both the 3rd and 4th steps of Estonian methodology. The Estonian 5-th and British 4-th, as well as the Estonian 6-th and British 5-th step are in conformance with each other. The 7-th step of Estonian methodology covers the actions, which are self-evidently conducted in the British approach, but not brought out as a step. The same could be mentioned about the 6-th step of British methodology from the viewpoint of the Estonian treatment. The steps of the risk assessments are brought comparatively in table 1 . 
Table 1: $\quad$ Comparison of the steps of risk assessments in Estonia and UK.

\begin{tabular}{|c|l|l|}
\hline Step & \multicolumn{1}{|c|}{ Estonia } & \multicolumn{1}{c|}{ UK } \\
\hline $\mathbf{1}$ & Collecting information & Contextualisation \\
\hline $\mathbf{2}$ & $\begin{array}{l}\text { The clearing up of possible } \\
\text { accidents }\end{array}$ & $\begin{array}{l}\text { Hazard review and allocation for } \\
\text { assessment }\end{array}$ \\
\hline $\mathbf{3}$ & $\begin{array}{l}\text { The assessment of possible } \\
\text { accident's probability }\end{array}$ & Risk analysis \\
\hline $\mathbf{4}$ & $\begin{array}{l}\text { The assessment of possible } \\
\text { accident's consequences }\end{array}$ & Risk evaluation \\
\hline $\mathbf{5}$ & Risk evaluation & Risk treatment \\
\hline $\mathbf{6}$ & $\begin{array}{l}\text { The arrangement of prevention } \\
\text { methods }\end{array}$ & Monitoring and reviewing \\
\hline $\mathbf{7}$ & $\begin{array}{l}\text { Forming of risk assessment } \\
\text { outcomes and compilation of } \\
\text { the report }\end{array}$ \\
\hline
\end{tabular}

\subsection{Risk types and categories}

The Estonian methodology requires the determination and risk assessment of $16+n$ different types of possible accidents (or hazards of those). These are the following: fires, explosions, transport accidents, accidents with dangerous chemicals, drinking water pollution, accidents on water bodies, accidents involving communal systems, breakdowns of electricity supply, breakdowns of communication systems, gas accidents, floods, collapses (buildings), extreme environmental conditions, epidemics, epizootics, social hazards, and the like, which means possible hazards that are actual but not in the main list.

The British methodology presumes the characterising of risk types with the risk identifier and risk category which responds to a certain numeric code. Risk identifiers have the following variants:

- H - hazards which will require a national as well as local response;

- HL - hazards which would not ordinarily prompt a national response, and would usually be dealt with locally;

- T - threats, which will require a national as well as local response.

The risk categories and codes are not defined in the methodology and its annexes (or more precisely in the publicly available version of it, used in our study). Browsing of concrete community risk registers brought out 10 main categories on which the concrete hazards are based. These are: industrial accidents and environmental pollution, transport accidents, severe weather, structural, human health, animal health, public protest, industrial action, international events and industrial technical failure.

\subsection{Assessing the likelihood}

The methodologies of both countries evaluate the likelihood with 5-level scales (Tables 2 and 3). 
Table 2: Likelihood assessment criteria in Estonian risk assessment.

\begin{tabular}{|c|l|l|}
\hline Level & Likelihood & Frequency \\
\hline 1 & Improbable & Less than once during 25 years \\
\hline 2 & Rare & At least once during 25 years \\
\hline 3 & Probable & At least once during 5 years \\
\hline 4 & Very probable & At least once a year \\
\hline 5 & Frequent & At least once a month \\
\hline
\end{tabular}

Table 3: Likelihood assessment criteria in British risk assessment.

\begin{tabular}{|c|c|c|c|}
\hline Level & Descriptor & Likelihood over 5 years & $\begin{array}{c}\text { Likelihood over 5 } \\
\text { years }\end{array}$ \\
\hline 1 & Negligible & $>0.005 \%$ & $>1$ in 20,000 chance \\
\hline 2 & Rare & $>0.05 \%$ & $>1$ in 2,000 chance \\
\hline 3 & Unlikely & $>0.5 \%$ & $>1$ in 200 chance \\
\hline 4 & Possible & $>5 \%$ & $>1$ in 20 chance \\
\hline 5 & Probable & $>50 \%$ & $>1$ in 2 chance \\
\hline
\end{tabular}

The Estonian approach uses the frequencies of the occurrence of accidental events. At the same time no additional conditions exist, which enables various interpretations. The reason being that the area where the possible accident (realized hazard) takes place can be chosen randomly: a city, a county, Estonia, EU, Europe, North America etc., and the frequency depends largely on the size of the surveyed territory. The British approach takes a certain time period of 5 years and sets the percentage and /or ratio of the accidental event. Simultaneously, originating directly from the public version of the methodology, the meaning of the entirety $(100 \%)$ remains unclear, which could be understood for example as the number of accidents per some kinds of ordinary events.

\subsection{Assessing the consequences}

The methodologies of both countries under observation use a 5-level assessment of the consequences. The evaluation scales are comparatively shown in table 4.

Table 4: Consequences assessment criteria in risk assessment methodologies.

\begin{tabular}{|l|l|l|l|}
\hline \multicolumn{2}{|c|}{ Estonia } & \multicolumn{2}{c|}{ United Kingdom } \\
\hline Level & Descriptor & Level & Descriptor \\
\hline A & Missing & 1 & Insignificant \\
\hline B & Limited & 2 & Minor \\
\hline C & Serious & 3 & Moderate \\
\hline D & Hard & 4 & Significant \\
\hline E & Very hard & 5 & Catastrophic \\
\hline
\end{tabular}


The comparison demonstrated the principal similarity, although the levels are defined and the descriptors named differently. The categories of consequences are also defined in different manners but a detailed comparison of the meanings and contents of the terms exhibited an almost direct conformance between the categories as displayed in table 5.

Table 5: $\quad$ The consequence (impact) categories.

\begin{tabular}{|l|l|}
\hline Estonia & United Kingdom \\
\hline Categories of consequences & Categories of impact \\
\hline Life and health & Health \\
\hline Vitally important sectors & Social \\
\hline Environment & Environment \\
\hline Property & Economic \\
\hline
\end{tabular}

\subsection{Risk assessment outcomes and outputs}

The Estonian methodology requires the compilation of an output document (summary or report) with the following statutory elements: area characterisation, maps and schemes of the area, accident statistics, environmental impacts, data of previously existing risk assessments (of concrete objects), risk assessment of accidents and appendixes (risk matrix, risk tables and risk map). The publication of the document is not mandatory.

The British legislation insists the Category 1 responders' creation and maintenance of a community risk register (CRR). The regulation [Regulation 2004] does not precisely define what the CRR is. Therefore we understand it (after having studied the concrete CRR-s) in two ways: firstly as a database with a predetermined structure in the form of table (the narrower sense) and secondly a document containing, in addition to the table, textual parts like introduction, purpose, context, explanation of assessment criteria etc. and usually the risk matrix, filled with risk evaluation outcomes (the broader sense).

The methodologies of both of the studied countries anticipate tables with a certain structure and risk matrixes for risk assessment and evaluation. The Estonian approach assumes the composition of a separate table for each risk, but does not require the compilation of a unified complex table like the CRR in the UK. At the same time British methodology affords an individual risk assessment example for documenting definite assessments and supporting the CRR. This example has comparable features with the Estonian risk table (for each assessed risk). The risk matrix in Estonian methodology has the scale of likelihood on the vertical axis and the scale of consequences on the horizontal axis. The allocation of the scales on the British risk matrix is the opposite. The likelihood levels are marked with numbers (1-5) and the consequence levels with letters (A-E) on the Estonian risk matrix and both scales are marked with numbers (1-5) on the British risk matrix. The British risk matrix (Figure 1) displays the four categories of risk ranking with explanatory keys. The current Estonian risk matrix does not originally contain the risk ranking divisions, which enables a creative approach to the problem on the one hand but complicates the comparison of risk 
assessments on the other. The "pure" risk matrix form of the methodology is displayed in Figure 2 using the example of Narva, where risk ranking was not determined on the matrix.

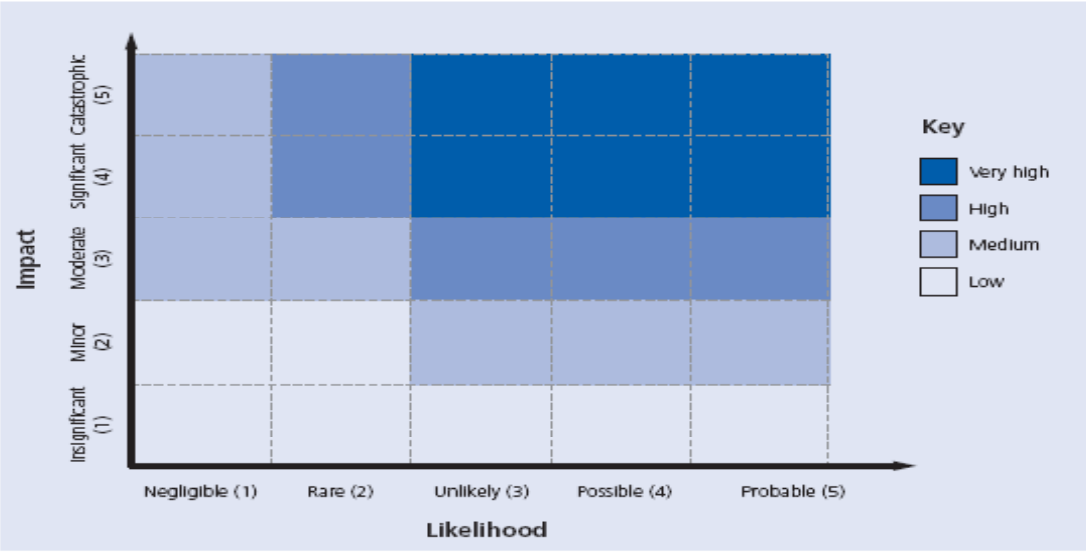

Figure 1: $\quad$ British risk matrix [14].

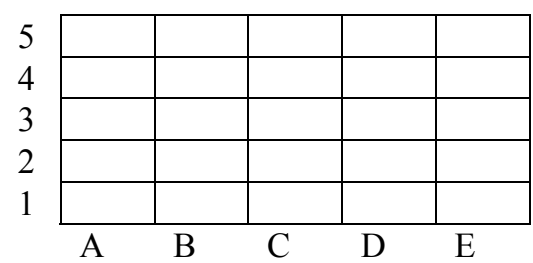

Figure 2: $\quad$ Risk matrix of Narva.

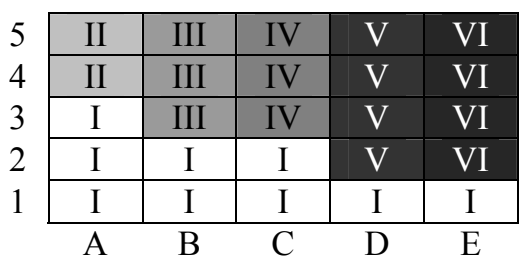

Figure 3: Risk matrix of Tallinn.

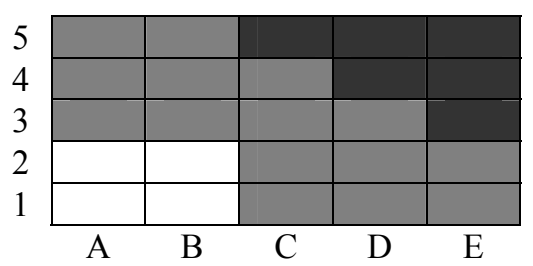

Figure 4: $\quad$ Risk matrix of Tartu.

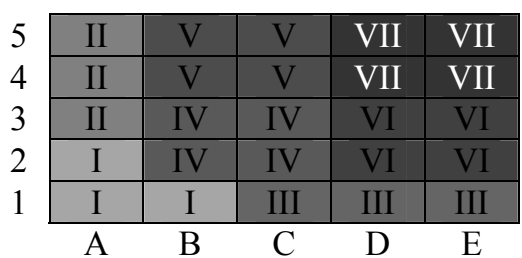

Figure 5: $\quad$ Risk matrix of Pärnu.

\section{Comparison of city risk assessments}

\subsection{General remarks}

The comparison of the risk assessments of the selected study areas: (cities, boroughs, conurbations) was performed mostly on the basis of publicly available materials via the Internet. The exceptions were the risk assessment outputs of the 
Estonian cities Tartu and Narva (together with Vaivara municipality), which have no direct open access by web but are still easily accessible for research purposes. London has six different local resilience areas, divided by boroughs, of which each has its own CRR and so we studied all of these. During the comparison, the same characteristics as in the comparison of the methodologies were under observation.

\subsection{Steps of risk assessment}

The steps of risk assessments in all the case studies were in conformance with those required in the corresponding methodologies of the two countries as much as it could be concluded on the basis of available outputs.

\subsection{Risk types and categories}

During the observation of the treatment of accident (hazards) categories variations emerged in the risk assessments of Estonian cities. The types of risks and categories of hazards in the risk assessments of British cities originated directly from the methodologies. In the Estonian approaches, the main structure of the accidents list was transformed from the original of the methodologies $(16+n)$ for the risk assessments of Tallinn [17,18] and Pärnu [19], and subcategories were added to the modified main categories. The risk references responding to categories of accidents (hazards) were similarly to the British, marked with the combinations of letters and numbers in the risk assessment of Tallinn but in another way: the letter showed the accident main type and the number the concrete accident (R1, R2; M1, M2, M2.1 etc.). The sub-categories of the original main categories were appended in the risk assessments of Tartu [20] and Narva [21]. The main accident (hazard) categories and sub-categories were marked with numbers in the form of two-step classification $(1: 1.1,1.2 ; 2$ : 2.1, 2.2 etc.).

\subsection{Likelihood assessment}

The criteria for likelihood assessment in the methodologies were directly followed by all the studied British risk assessments. The risk assessments of Estonian cities again contained more variability or more precisely - Tallinn had developed its own modification of the methodology, where the frequency range was from: more than once a year up to rarer than once per 100 years. The risk assessments of other studied Estonian cities followed the likelihood scale of the original methodology.

\subsection{Consequences (impact) assessment}

The certain impact categories, as defined in the methodologies, were followed in risk assessments of the British cities. The same could be said about the three Estonian cities except Tallinn where modification of the methodology defined two additional components to the four, compared beforehand with British 
analogues. These areas were the (need for) evacuation and (presence of or coverage with) rescue resources.

\subsection{Risk assessments performance, availability, outcomes and outputs}

Although the responsibility for the performance of risk assessment of a city or community in Estonia lies with the local governments, the real practical executors can be different persons, who have reciprocal agreements. For instance the risk assessment of Tallinn was carried out mainly by specialists of the crisis management service of the (previous) Tallinn Fire and Rescue Department (whose functions have been replaced by the crisis management bureau of the North-Estonian Rescue Centre). The risk assessment of Tartu was conducted by a research team from the Estonian University of Life Sciences with the participation of the authors of the current paper. The risk assessment of Pärnu was accomplished under the coordination of crisis management specialists of the rescue service, but different offices and persons were involved. The risk assessment of Narva was carried out mostly by private consultants. All the risk assessments of the four British cities or conurbations were performed by Local Resilience Forums, formed by Category 1 responders (or more precisely by working groups formed by previously mentioned institutions on the basis of Category 1 and Category 2 responders) as required by the Act [9]. The risk assessments were studied through publicly available community risk registers and therefore we had no detailed information about the exact staff of these working groups.

The risk assessment output documents (reports or summaries) of Tartu, Narva and Pärnu follow the formal structure enacted in the methodology. The risk assessment report of Tallinn is the most substantial with its two parts, but only partially complies with the previously mentioned structure. For instance there is no special chapter for emergencies statistics but at the same time there exists a special chapter for the (previously referred modification of) methodology. The British cities CRRs, in the narrower sense, originate comparatively accurately from the settings of the methodology and the examples of its annexes. The CRRs in a broader sense have more variations, considering the constitution and additional textual parts. For example the CRRs of (the boroughs of) London [22-27] include the contextualisation statement chapter, describing the social and environmental factors and economic and transport infrastructures. The included textual part of the Greater Manchester CRR [28] is on the contrary very laconic, but simultaneously there exists additional material: The Great Manchester Profile Document [29] which functionally belongs together with the CRR.

The risk assessment reports of Tallinn and Pärnu are available on the homepages these city governments. The risk assessment reports of Tartu and Narva are available upon request to the city governments, having currently no open access via Internet. The CRRs of the London (boroughs) and Greater Manchester can be downloaded from special sites of the homepages of the responding fire departments or brigades. The CRRs of West Midlands [30] and Belfast [31] can be found from special sites of the local resilience forums. 
Hereby, it should be mentioned that West Midlands had no complete version of CRR, but only preliminary materials, covering partly the essential elements of the CRR. We began from these in our research.

As the risk matrices are core elements of the risk assessments, the ongoing comparative description is mainly based on these. The risk matrix is not only a risk evaluation tool, but also an output form, filled with risk evaluation and rating results. The risk assessments of Estonian cities in general use uniform risk matrices, but diversity is recognised in the approaches to risk ranking. The (blank) risk matrix of Narva (Figure 2) represents the original one from the methodology - without determined risk ranking zones. The (blank) risk matrix of Tallinn (Figure 3) is divided into 6 (I-VI) risk ranking zones. Analogically with the British risk matrix, the relative importance of the consequences is accentuated, but probably with too high a degree of contrast. For example in the case of catastrophic consequences, the events with a small likelihood belong to the VI zone (the highest) and the same with very small likelihood to the Ist zone (lowest). The (blank) risk matrix of Tartu (Figure 4) uses the 3 risk ranking zones on the matrix (originally red, yellow and green), where likelihood and consequences have proportional weights. The (blank) risk matrix (Figure 5) of Pärnu uses 7(I-VII) risk-ranking zones. In our mind the last has aberrances from the general logics of a risk matrix, where the risk increases "diagonally" towards the matrix, following the increase of the values of likelihood and consequences (or impacts). The risk assessments of the British cities followed the uniform risk ranking from the methodology.

The assessed risks were observed only cursorily in the current study, concentrating on (the comparison of) the highest assessed risks, because the results of the risks assessments of the two countries, as well as different regions of Estonia, were not comparable one-for-one. The highest risks in risk assessments of Estonian cities were in general: fire risks, chemical accidents risks in transport and fixed installations, failures of vitally important networks, extreme environmental conditions, and epidemics (except Tallinn, where the last was not assessed). Typical examples of very high risks in risk assessments of the British cities and conurbations, which were brought out in all or most studied cases (including the CRRs of London boroughs), were: influenza type disease with pandemic course, industrial technical failures of telecommunication infrastructure and/or electricity network, major local fluvial flooding.

\section{Conclusions}

The previous study demonstrated that the methodological approaches and the risk assessment outcomes and outputs of the two countries were readily comparable, as was proposed. The Estonian territorial risk assessment methodology was more laconic and less precise which enabled various interpretations and, as the cases showed, a creative approach. In general parallels can be drawn between the main steps of risk assessment in the methodologies of the studied countries. The positive side of the latter- is the generation of new ideas and viewpoints for the further development of the methodology. At the same time a drawback is the noticeable variability and difficult comparability of 
the outcomes. The British risk assessment methodology was more voluminous and detailed and the work arrangement was firmly enacted. This ensured the principally uniform approach amongst the essential components of the risk assessments of the cities, as was noticed in the studied cases.

In our opinion the current Estonian territorial risk assessment methodology needs improvement. We believe that during the development and further specification of the Estonian territorial risk assessment methodology more attention has to be turned to the following components: the classification of hazards (and/or accidents caused by these), risk matrix from the aspects of risk ranking, and likelihood assessment. We find that the British methodology is suitable for serving as one indirect example for that purpose.

The optimal classification of categories of accidents (hazards) should be 2step and the possible variants could be the combination of a letter and a number (A: A1, A2; B: B1, B2 etc) as in the case of Tallinn and alternatively the 2-step numeration (1: 1.1, 1.2; $2: 1.2,2.2$ etc) as in the cases of Tartu and Pärnu. The British system of codes and categories seems too complicated and specific to adopt directly.

The risk ranking as we visualize it, could be 3-level: low, medium, high or 5level, involving two intermediate levels. Two variations could be conceivable: firstly, where the likelihood and consequences are in "balance" like in the case of Tartu (Figure 3) and secondly, where the weight of consequences is expressed more, like the British and Tallinn cases (Figures 1 and 3). The latter could be considered because of the fact that adequate response to single accident(s) with multiple victims is on average more complicated due to the lack of resources for simultaneous application rather than multiple accidents with few victims.

The likelihood assessment tools could be equipped with supplementary limiting criteria in addition to frequency, like commitment with certain territorial units (per $\mathrm{n} \mathrm{km}^{2}$ ), etc. The application of similar principles as the British use is also conceivable, but this presumes an adjustment of the circumstances beforehand.

Finally we emphasize, that the accurate determination of work arrangements, publication requirements and conditions, as well as information exchange and cooperation in the field of civil protection with other EU countries will be conducive to the perspectives of Estonian territorial risk assessment.

\section{Acknowledgements}

This study was supported by the Target Funding Project No. 1090050s07 of the Ministry of Education and Science, Estonia. The authors would like to thank Tõnu Paasoja from Tartu Aviation College and Evelin Uiga from Risk Management OÜ company for their help with the expert advise and city governments of Narva and Tartu for cooperativeness. 


\section{References}

[1] Tammepuu, A., Sepp, K. \& Uiga, E., Aspects of risk assessment in land use planning: the case study of Tartu. Safety and Security Engineering II, ed. M. Guarascio, WIT Press: Southampton, UK, pp 345 - 357, 2007.

[2] Lonka, H., Report on risk assessment procedures used in different European Union countries and in Norway, 39 s., Publication of the Finnish Ministry of Interior16/1999. http://europa.eu.int/comm/environment/civil/ pdfdocs/riskassfinrep.pdf

[3] Council directive 96/82/EC of 9 December 1996 on the control of majoraccident hazards involving dangerous substances, OJ No L 10 of 14 January 1997 (Seveso II-Directive), and Directive 2003/105/EC of the European Parliament and of the Council of 16 December 2003 amending Council directive 96/82/EC, OJ of 31 December 2003.

[4] Treu, M.C., Colucci \& Lodrini, S. Territorial vulnerability analysis: the methodological framework. Risk Analysis IV, ed. C. A. Brebbia, WIT Press: Southampton, UK, pp 754 - 761, 2004.

[5] Treu, M. C. \& Colucci, A., Territorial vulnerability and local risks. Sustainable Development and Planning II, Vol. 2, eds: C. A. Brebbia, \& A. Kungolos, WIT Press: Southampton, UK, pp. 1261 - 1268, 2005.

[6] Baldi, C., Martelli, M \& Treu, M. C., Territorial vulnerability analysis: the Environmental Risk Management Systems. Risk Analysis IV, ed. C. A. Brebbia, WIT Press: Southampton, UK, pp 747 - 752, 2004.

[7] Tint, P., Munter, R., Lavrentjev, J., Siirde, A., Möller, K. \& Siirak, V. Risk Management of Major Accident Hazards in Estonia. Proceedings of the 3rd Safety and Reliability International Conference (KONBIN 2003), Gdynia, Poland, 2003.

[8] Emergency Preparedness Act. State Gazette I, 95, 613, 2000.

[9] Civil Contingencies Act 2004 (c.36). The Stationery Office Limited, 2004.

[10] Civil Contingencies Act 2004: a short guide (revised). Cabinet Office, Civil Contingencies Secretariat. http://www.ukresilience.gov.uk/ /media /assets/www.ukresilience.info/15mayshortguide\%20pdf.ashx

[11] The Civil Contingencies Act 2004 (Contingency Planning) Regulations 2005, Statutory Instrument 2005 No. 242, 2005. http://www.opsi.gov.uk /si/si2005/20052042.htm

[12] Maakonna ning valla ja linna riskianalüüsi metoodika [Methodology of risk assessment of the county, the municipality and the city]. Appendix to the State Gazette, 82, 1112, 2001.

[13] Hazard Identification and Evaluation in a Local Community, UNEP IE/PAC, 1992.

[14] Emergency Preparedness - Guidance on Part I of the Civil Contingencies Act 2004, its Associated Regulations and Non-Statutory Arrangements, HM Government, 2005. http://www.ukresilience.gov.uk/ /media/assets /www.ukresilience.info/emergprepfinal\%20pdf.ashx 
[15] Preparing Scotland: Scottish Guidance on Preparing for Emergencies, The Scottish Government Publications, 2006. http://www.scotland.gov.uk /Publications/2006/02/27140215/0

[16] A Guide to Risk Assessment in Northern Ireland (Draft). Office of the First Minister and Deputy Minister, 2005. http://www.ofmdfmni.gov.uk /aguidetoriskassessment.pdf

[17] Tallinna riskianalüüsi I osa [Risk assessment of Tallinn part I]. Tallinn Fire and Rescue Department, Crisis Management Service: Tallinn, 2004. http://www.tallinn.ee/est/g3552s25496

[18] Tallinna riskianalüüsi II osa [Risk assessment of Tallinn part II]. Tallinn Fire and Rescue Department, Crisis Management Service: Tallinn, 2005. http://www.tallinn.ee/est/g3552s25498

[19] Pärnu linna riskianalüüs [Risk assessment of Pärnu city]. Pärnu City Government: Pärnu, 2004. http:/www.parnu.ee/fileadmin /user_upload/materjalid/LINNA_RISKIANALYYS.pdf

[20] Tartu linna riskianalüüs, [Risk assessment of Tartu city] Estonian University of Life Sciences, Institute of Technology: Tartu, 2006.

[21] Narva linna ja Vaivara valla esialgne riskianalüüs [Preliminary risk assessment of Narva city and Vaivara municipality]. Ants Tammepuu FIE: Tartu, 2004.

[22] North West London Local Resilience Forum, Community Risk Register, Version 1.3, 2008. http://www.london-fire.gov.uk/about_us/media /crrnw.pdf

[23] North Central London Local Resilience Forum, Community Risk Register, Version 1.3, 2008. http://www.london-fire.gov.uk/about_us/media /crrnc.pdf

[24] North East London Local Resilience Forum, Community Risk Register, Version 1.3, 2008. http://www.london-fire.gov.uk/about_us/media /crrne.pdf

[25] Central London Local Resilience Forum, Community Risk Register, Version 1.4, 2008. http://www.london-fire.gov.uk/about_us/media /crrcentral.pdf

[26] South East London Local Resilience Forum, Community Risk Register, Version 1.4, 2008. http://www.london-fire.gov.uk/about_us/media/crrse.pdf

[27] South West London Local Resilience Forum, Community Risk Register, Version 1.4, 2008. http://www.london-fire.gov.uk/images/crrsw.pdf

[28] The Greater Manchester Community Risk Register 2006/7. http:/www.gmep.org.uk/ccm/cms-service/download/asset/?asset_id=607004

[29] The Greater Manchester Profile Document 2006/7. http:/www.gmep.org.uk/ccm/cms-service/download/asset/?asset_id=607005

[30] Community Risk Register for West Midlands Conurbation. http://www.wmfs.net/crr.xtml

[31] Community Risk Register and Matrix for Belfast City Council Area: Public Version. Belfast Resilience: 2008. http://www.belfastresilience.co.uk/Belfast $\% 20$ CRR $\% 202008 \% 20$ Public $\% 2$ 0Web\%20Version.pdf 